\title{
Combination therapy using oral S-1 and targeted agents against human tumor xenografts in nude mice
}

\author{
MAMORU NUKATSUKA ${ }^{1}$, HITOSHI SAITO ${ }^{2}$, FUMIO NAKAGAWA ${ }^{2}$, HIROAKI TSUJIMOTO $^{3}$, \\ KAZUKI SAKAMOTO ${ }^{3}$, SAYAKA TSUKIOKA ${ }^{3}$, JUNJI UCHIDA ${ }^{2}$, MAMORU KINIWA ${ }^{2}$, \\ TAKASHI KOBUNAI ${ }^{1}$ and TEIJI TAKECHI ${ }^{4}$ \\ ${ }^{1}$ Oncology Medical Affairs Division, Taiho Pharmaceutical Co., Ltd., Tokushima 771-0194; \\ ${ }^{2}$ Tokushima Research Center, Taiho Pharmaceutical Co., Ltd., Tokushima 771-0194; \\ ${ }^{3}$ Tsukuba Research Center, Taiho Pharmaceutical Co., Ltd., Okubo Tsukuba-Shi, Ibaraki 300-2611; \\ ${ }^{4}$ Oncology Medical Affairs Division, Taiho Pharmaceutical Co., Ltd., Tokyo 101-0047, Japan
}

Received November 30, 2011; Accepted January 13, 2012

DOI: $10.3892 /$ etm.2012.484

\begin{abstract}
In this study, combination therapies using the oral fluoropyrimidine tegafur-gimeracil-oteracil (S-1) with several targeted agents or antibodies, were evaluated. First, the effects of tyrosine kinase inhibitors (erlotinib hydrochloride, sorafenib tosilate and sunitinib malate) against human nonsmall cell lung cancer (NSCLC), breast cancer and colorectal cancer were evaluated in vivo. The effects of the combination of S-1 and targeted antibodies (bevacizumab and cetuximab) against human colorectal cancers was also evaluated in vivo. S-1 and the epidermal growth factor receptor (EGFR) tyrosine kinase inhibitor, erlotinib, showed a significant inhibition of growth in human NSCLC (Lu-99 and PC-9 cell lines). The antitumor activity of the combination of $\mathrm{S}-1$ and erlotinib against Lu-99 and PC-9 cancer cell lines was significantly superior to either monotherapy $(\mathrm{P}<0.05)$. Combination therapy using the multi-tyrosine kinase inhibitors, sorafenib or sunitinib, with S-1 against breast cancer (MX-1 cell line) and NSCLC (NCI-H460 cell line) was significantly superior to either monotherapy $(\mathrm{P}<0.01)$. The combination of the anti-vascular endothelial growth factor antibody bevacizumab or the anti-EGFR antibody, cetuximab, with S-1 against human
\end{abstract}

Correspondence to: Dr Mamoru Nukatsuka, Oncology Medical Affairs Division, Taiho Pharmaceutical Co., Ltd., 224-2 Ebisuno Hiraishi, Kawauchi-Cho Tokushima-Shi, Tokushima 771-0194, Japan E-mail: m-nukatsuka@taiho.co.jp

Abbreviations: DIF, DPD inhibitory fluoropyrimidine; DPD, dihydropyrimidine dehydrogenase; EGFR, epidermal growth factor receptor; GDP, growth delay period; HPMC, hydroxypropyl methylcellulose; NSCLC, non-small cell lung cancer; RTV, relative tumor volume; S-1, tegafur-gimeracil-oteracil; TGI, tumor growth inhibition; TS, thymidylate synthase; UFT, uracil and tegafur; VEGF, vascular endothelial growth factor

Key words: S-1, combination chemotherapy, human tumor xenograft, targeted agents, growth delay period colorectal cancer [Col-1, KM20C (bevacizumab) and DLD-1 (cetuximab) cell lines] and a 5-fluorouracil (5-FU)-resistant cell line (KM12C/5-FU) was significantly superior to either monotherapy $(\mathrm{p}<0.01)$. In particular, the growth of the Col-1 cells was completely inhibited by the combination of S-1 and bevacizumab. No toxic mortalities and no significant difference in the body weight changes of the animals treated with S-1 combined with the targeted agents or with the monotherapies were observed; therefore, the treatments appeared to be well-tolerated. Our preclinical findings indicate that the combination therapies of S-1 and targeted agents are promising treatment options.

\section{Introduction}

New targeted agents, i.e., targeted antibodies and tyrosine kinase inhibitors, have been developed and used clinically against various cancers (colorectal, lung, kidney and breast cancer, etc.). As the antitumor activity of these agents originates from anti-angiogenesis or the inhibition of growth signals, and thus differs from that of traditional chemotherapeutic agents, these targeted agents reportedly enhance antitumor activity when used in combination with chemotherapy by means of their different mechanisms (1-5).

Tegafur-gimeracil-oteracil (S-1), an oral fluoropyrimidine, is composed of $1 \mathrm{M}$ tegafur [a masked form of 5-fluorouracil (5-FU)], 0.4 M 5-chloro-2, 4-dihydroxypyrimidine [gimeracil, a potent inhibitor of the 5-FU degradation enzyme dihydropyrimidine dehydrogenase (DPD) in the liver and tumor tissues] and $1 \mathrm{M}$ potassium oxonate (oteracil, which mainly inhibits the phosphorylation of 5-FU in the gastrointestinal tract) (7). S-1 has been clinically shown to be effective against various human cancers (8) and to have a potent antitumor efficacy, with a low gastrointestinal toxicity, against various types of cancers (9-11). Several combination chemotherapies using S-1 and cytotoxic agents, including irinotecan (12), CDDP (13) and taxanes $(14,15)$, have been reported to be clinically effective. In addition, when used in combination with the targeted agent gefitinib (16), the expression of the thymidylate synthase (TS) 
protein and mRNA was decreased in a time-dependent manner in the presence of $5 \mu \mathrm{M} 5-\mathrm{FU}$ in 3 human non-small cell lung cancer (NSCLC) cell lines (Ma-1, Ma-53 and NII-H460) and the antitumor activity of S-1 was potentiated by the combined therapy. Furthermore, the exposure of the human epidermal growth factor receptor 2 (HER2) amplification-positive human gastric cancer cell lines (NCI-N87 and 4-1ST) to S-1 and epidermal HER2 inhibitors (lapatinib and trastuzumab) resulted in the downregulation of TS expression in a concentration-dependent manner. The antitumor activity of S-1 was increased significantly in the combined therapy in vivo (17).

In this study, we evaluated the effects of S-1 used in combination with several targeted agents (three kinase inhibitors and two antibodies) in vivo. This was achieved by determining the tumor growth inhibition (TGI) ratio and the growth delay period (GDP) and examining the correlation between antitumor activity and the tumoral expression of DPD.

\section{Materials and methods}

Agents. Tegafur, gimeracil, oteracil and sunitinib malate (sunitinib) were synthesized in our laboratory. Sorafenib tosilate (sorafenib) and cetuximab were purchased from Kemprotec Ltd. (Middlesbrough, UK) and Merck Serono Co., Ltd. (Zug, Switzerland), respectively. Bevacizumab and erlotinib hydrochloride (erlotinib) were purchased from Roche Ltd. (Basel, Switzerland). Cremophor ${ }^{\circledR}$ was purchased from Nacalai Tesque, Inc. (Kyoto, Japan). All other agents were commercially available products of the highest grade.

Tumor xenografts. The human large cell lung cancer cell line Lu-99 was purchased from the Health Science Research Resources Bank (Tokyo, Japan) and the human lung differentiated adenocarcinoma cell line PC-9 was provided by Showa University (Tokyo, Japan). The human large cell lung cancer cell line NCI-H460 was purchased from the American Type Culture Collection (Rockville, MD, USA). The human colorectal cancer cell line DLD-1 was purchased from DS-Pharma Biomedical Co. Ltd. (Osaka, Japan). The 5-FU-resistant human colorectal cancer cell line, KM12C/5-FU, was established in our laboratory, as described previously (18). The human breast cancer cell line MX-1, the colorectal cancer cell line Col-1 and the large cell lung cancer cell line LC-11 were obtained from the Central Institute for Experimental Animals (Kawasaki, Japan). No KRAS mutations in Lu-99, KM12C and DLD-1 and no EGFR mutation in Lu-99 were observed, but NCI-H460 carried a KRAS mutation (19).

Antitumor activity in vivo. Male nude mice were purchased from CLEA Japan Inc. (Tokyo, Japan) or Charles River Japan Inc. (Yokohama, Japan) and were housed under specific pathogen-free conditions, with food and water provided ad libitum. Following a 1-week quarantine period, the animals were implanted subcutaneously with a solid human tumor, the volume of which was $\sim 8 \mathrm{~mm}^{3}$. In order to evaluate the antitumor activity, the mice were randomized according to the tumor volume once the mean tumor volume reached $\sim 150-200 \mathrm{~mm}^{3}$ (day 0). Each group consisted of 6-8 nude mice.

S-1 was prepared by mixing tegafur, gimeracil and oteracil at a molar ratio of 1:0.4:1 in $0.5 \%$ hydroxypropyl methylcel- lulose (HPMC) and was administered orally once daily on days 1-14. S-1 (6.9-8.3 mg) was administered at the reported effective dose in mice (7).

Erlotinib, suspended in 0.5\% HPMC, was administered orally on days $1,4,8$ and 11 at $100 \mathrm{mg} / \mathrm{kg}$ in mice carrying an Lu-99 xenograft, according to the reported effective dose (20). For PC-9, which carries an EGFR mutation that is supposedly more sensitive to erlotinib (21), erlotinib was administered at a dose of $12.5 \mathrm{mg} / \mathrm{kg}$. Sorafenib, dissolved with $8.3 \%$ cremophor and $8.3 \%$ ethanol, or sunitinib, dissolved in $20 \mathrm{mM}$ citrate buffer at $\mathrm{pH} 3.5$, was administered orally once daily on days $1-14$ at a dose of 15 and $20 \mathrm{mg} / \mathrm{kg}$, respectively $(18,19)$. Cetuximab and bevacizumab were diluted with saline and administered intraperitoneally on days $1,4,8$ and 11 at 40 and $5 \mathrm{mg} / \mathrm{kg}$, respectively $(22,23)$.

The tumor diameters were measured twice a week and the tumor volume was estimated as $0.5 \mathrm{x}$ length $\mathrm{x}$ width ${ }^{2}$. The relative tumor volume (RTV) was calculated using the following formula: RTV = (tumor volume on measured day)/(tumor volume on day 0 ). On day 15 , the TGI ratio was calculated using the formula: TGI $=[1$ - (mean tumor volume of treated group)/(mean tumor volume of control group)] x 100. The antitumor activity was evaluated based on the GDP (24), which is the difference in the time taken for the tumors to reach $\sim 25 \%$ of the size of the control (the RTV value used to estimate the GDP was designated as 2 for Lu-99; 5 for MX-1, NCI-H460 and KM12C/5-FU; and 3 for Col-1, KM20C and DLD-1). However, as the growth of PC-9 was slower than that of the other tumors, the GDP was evaluated when the RTV reached 2 . The period during which the RTV of the treated group reached $25 \%$ of the control on day 15 was calculated using linear regression, as reported previously (24). The expected GDP of the combined group was calculated using the formula: expected GDP of combined group $=($ GDP of S-1 group $)+($ GDP of combined reagent). If the observed GDP of the combined group was superior to the expected value, the combination was designated as more than additive. The relative body weight change (BWC) was calculated using the following formula: BWC (\%) $=[($ body weight on day 15$)-($ body weight on day 0$)] /($ body weight on day 0) x 100. Cases in which the BWC was $<-20 \%$ were regarded as having received toxic regimens.

The animal studies were performed according to the guidelines and with the approval of the Institutional Animal Care and Use Committee of Taiho Pharmaceutical Co., Ltd.

Real-time reverse transcription $(R T)$-polymerase chain reaction (PCR) for DPD in tumor tissues. Total RNA was isolated from the residual section of the tumor tissue and first-strand cDNA was synthesized from $500 \mathrm{ng}$ of total RNA using the High-Capacity cDNA Archive kit, as described by the manufacturer, using i-cycler. Real-time RT-PCR was performed using the QuantiTect Probe PCR kit and ABI PRISM 7900HT Sequence Detection system, according to the manufacturer's instructions. Briefly, $2 \mathrm{ng}$ of cDNA was added to a reaction mixture containing $12.5 \mu \mathrm{l}$ of $2 \mathrm{X}$ QuantiTect Probe PCR master mix and $1.25 \mu \mathrm{l}$ of $20 \mathrm{X}$ TaqMan gene expression assays mix in a final volume of $25 \mu \mathrm{l}$. The conditions for the real-time RT-PCR were: 1 cycle of $50^{\circ} \mathrm{C}$ for $2 \mathrm{~min}$ and $95^{\circ} \mathrm{C}$ for $15 \mathrm{~min}$; 40 cycles of $94^{\circ} \mathrm{C}$ for $15 \mathrm{sec}$ and $60^{\circ} \mathrm{C}$ for $1 \mathrm{~min}$. Gene expression profiling was achieved using the comparative 
Table I. Antitumor activity and body weight changes in mice implanted with human non-small cell lung cancer tumors from the cell lines, Lu-99 or PC-9, following treatment with S-1 and the EGFR kinase inhibitor, erlotinib.

\begin{tabular}{|c|c|c|c|c|c|c|c|}
\hline \multirow{2}{*}{ Tumor } & \multirow{2}{*}{$\begin{array}{c}\text { Drug } \\
(\mathrm{mg} / \mathrm{kg})\end{array}$} & \multirow{2}{*}{ Treatment } & \multirow{2}{*}{$\begin{array}{c}\text { Tumor volume } \\
\left(\mathrm{mm}^{3}, \text { mean } \pm \mathrm{SD}\right)\end{array}$} & \multirow{2}{*}{$\begin{array}{l}\mathrm{TGI}^{\mathrm{b}} \\
(\%)\end{array}$} & \multirow{2}{*}{$\begin{array}{l}\mathrm{GDP}^{\mathrm{c}} \\
\text { (days) }\end{array}$} & \multicolumn{2}{|c|}{ Body weight change $^{\mathrm{d}}$} \\
\hline & & & & & & $(\mathrm{g}$, mean $\pm \mathrm{SD})$ & $(\%)$ \\
\hline \multirow[t]{4}{*}{ Lu-99 } & Control & - & $1257 \pm 196$ & - & 0.0 & $2.5 \pm 0.5$ & 10.1 \\
\hline & S-1 (8.3) & days $1-14$ & $728 \pm 94$ & 42.1 & 3.3 & $1.5 \pm 1.4$ & 6.0 \\
\hline & Erlotinib (100) & days $1-14$ & $747 \pm 177$ & 40.6 & 2.8 & $0.5 \pm 1.2$ & 2.3 \\
\hline & S-1 + erlotinib & & $563 \pm 60^{\mathrm{e}}$ & 55.3 & 7.0 & $-3.0 \pm 2.5 \mathrm{NS}$ & -13.0 \\
\hline \multirow[t]{4}{*}{ PC-9 } & Control & - & $661 \pm 95$ & - & 0.0 & $0.9 \pm 0.5$ & 3.0 \\
\hline & S-1 (10.0) & days $1-14$ & $427 \pm 20$ & 35.4 & 1.6 & $-0.09 \pm 0.8$ & -0.3 \\
\hline & Erlotinib (12.5) & days $1-14$ & $289 \pm 55$ & 56.4 & 8.8 & $0.4 \pm 0.9$ & 1.6 \\
\hline & S-1 + erlotinib & & $218 \pm 39^{e}$ & 67.0 & 10.9 & $-0.2 \pm 0.6 \mathrm{NS}$ & -0.5 \\
\hline
\end{tabular}

${ }^{a}$ Tumor volume on day 15 ; ${ }^{b}$ tumor growth inhibition ratio on day $15 ;{ }^{\mathrm{c}} \mathrm{GDP}$ is the difference in time taken for the RTV to reach 2.0 between the treated and the control groups; ${ }^{\mathrm{d}}$ relative body weight change between days 0 and 15 ; ${ }^{\mathrm{o}}$ overall maximal $\mathrm{P}<0.05$ by closed testing procedure using the Aspin-Welch t-test; NS, overall maximal P>0 .05 by closed testing procedure using the Aspin-Welch t-test; EGFR, epidermal growth factor receptor; GDP, growth delay period; RTV, relative tumor volume; S-1, tegafur-gimeracil-oteracil.
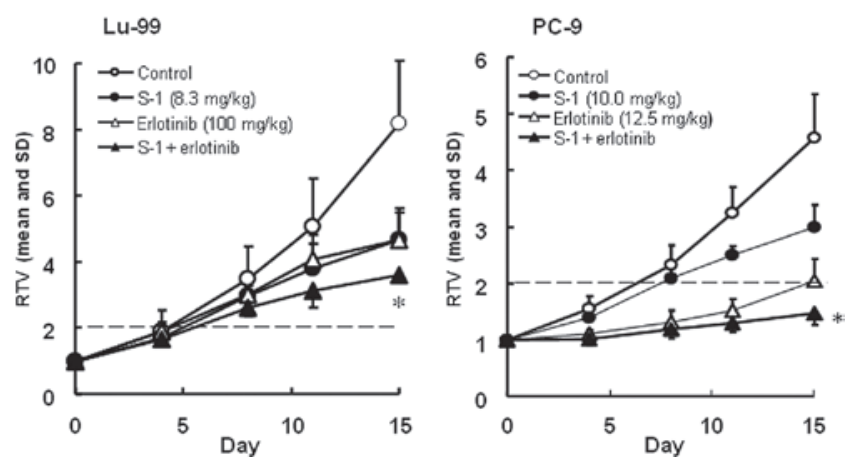

Figure 1. Tumor volume changes in human non-small cell lung cancer, (A) Lu-99 and (B) PC-9 cell lines, in vivo. Mice were randomized according to the tumor volumes on day 0 . The mice implanted with tumors from $\mathrm{Lu}-99$ and PC-9 cells were treated with the vehicle or S-1 at 8.3 or $10 \mathrm{mg} / \mathrm{kg}$ administered orally once daily on days $1-14$. Erlotinib at 100 or $12.5 \mathrm{mg} / \mathrm{kg}$, was administered orally, alone or in combination with S-1 on days 1-14. The tumor volume was measured twice a week. The values indicate the means \pm $\mathrm{SD}$ of the RTV $(\mathrm{n}=6)$. * Overall maximal $\mathrm{P}<0.05$ according to a closed testing procedure using the Aspin-Welch t-test. RTV, relative tumor volume. S-1, tegafur-gimeracil-oteracil.

cycle threshold method of relative quantification [the calibrator samples were untreated cells, with $\beta$-actin (ACTB) used as the endogenous control]. The Gene Assay IDs of the TaqMan gene expression assay were Hs00559278_m1 for DPD (DPYD) and Hs99999903_m1 for ACTB. The relative gene expression levels of DPD were calculated using the $\Delta$ threshold cycle $(\mathrm{Ct})$ method according to the formula shown below. The expression levels of estrogen receptor- $\alpha$ (ER- $\alpha$ ) were expressed as $2^{-\Delta \mathrm{Ct}} \mathrm{x}$ 100 for the ease of calculation, where $\Delta \mathrm{Ct}=(\mathrm{Ct}$ of DPD $)-(\mathrm{Ct}$ of ACTB).

Statistical analysis. The significance of the differences in the mean RTV between the treated and control groups on day 15 was analyzed using the Aspin-Welch two-tailed t-test. The combinational effect of targeted agents on the antitumor activity was analyzed according to a closed testing procedure using the Aspin-Welch two-tailed t-test (25) and EXSAS, ver. 7.11 (Arm Systex Co., Ltd., Osaka, Japan).

\section{Results}

Increased antitumor activity of $S-1$ in combination with EGFR kinase inhibitor against human NSCLC in vivo. The antitumor activities of S-1 and the EGFR kinase inhibitor erlotinib, which have been applied against NSCLC clinically, were evaluated. The RTV changes in the Lu-99 and PC-9 cancer cell lines are shown in Fig. 1.

The antitumor activity of the combination group on day 15 was significantly higher than that of either monotherapy group for Lu-99 $(\mathrm{P}<0.05)$ and PC-9 $(\mathrm{P}<0.05)$. The GDP values were lengthened in the combination group compared with the monotherapy groups. As the observed GDP values for the combined therapy (7.0 and 10.9 days for Lu-99 and PC-9, respectively) were not less than the expected values (6.1 and 10.4 days, respectively), the combination of S-1 with erlotinib was regarded as being additive (Table I). As the BWC was not $<-20 \%$ in any of the groups and no significant difference was observed between the combination therapy and either of the monotherapy groups, these combinations appeared to be tolerable.

Increased antitumor activity of $S-1$ in combination with tyrosine kinase inhibitors in vivo. The antitumor activities of S-1 and the multi-kinase inhibitors, sorafenib and sunitinib, were evaluated. The RTV changes of the MX-1 and NCI-H460 cancer cell lines treated with sorafenib are shown in Fig. 2. The RTV of the combination group on day 15 was significantly lower than that of either monotherapy group for the MX-1 and NCI-H460 cancer cell lines $(\mathrm{P}<0.01)$. As the GDP values for the combined therapy (6.0 and 5.4 days for the MX-1 and NCI-H460 cancer cell lines, respectively) were almost equivalent to the expected values (6.5 and 4.9 days, respectively), the combination of S-1 with erlotinib was regarded as being not competitive (Table II). 
Table II. Antitumor activity and body weight changes in mice implanted with tumors from human breast cancer MX-1 cells or human non-small cell lung cancer NCI-H460 cells, following treatment with S-1 and the multi-kinase inhibitor, sorafenib.

\begin{tabular}{|c|c|c|c|c|c|c|c|}
\hline \multirow{2}{*}{ Tumor } & \multirow[b]{2}{*}{$\begin{array}{l}\text { Drug } \\
(\mathrm{mg} / \mathrm{kg})\end{array}$} & \multirow{2}{*}{ Treatment } & \multirow{2}{*}{$\begin{array}{c}\text { Tumor volume } \\
\left(\mathrm{mm}^{3}, \text { mean } \pm \mathrm{SD}\right)\end{array}$} & \multirow{2}{*}{$\begin{array}{l}\text { TGI }^{\mathrm{b}} \\
(\%)\end{array}$} & \multirow{2}{*}{$\begin{array}{l}\mathrm{GDP}^{\mathrm{c}} \\
\text { (days) }\end{array}$} & \multicolumn{2}{|c|}{ Body weight change ${ }^{d}$} \\
\hline & & & & & & $(\mathrm{g}$, mean $\pm \mathrm{SD})$ & $(\%)$ \\
\hline \multirow[t]{4}{*}{ MX-1 } & Control & - & $2747 \pm 497$ & - & 0.0 & $4.2 \pm 0.9$ & 19.0 \\
\hline & S-1 (8.3) & days $1-14$ & $1832 \pm 112$ & 33.3 & 1.6 & $3.7 \pm 0.6$ & 16.7 \\
\hline & Sorafenib (15) & days $1-14$ & $1076 \pm 214$ & 60.8 & 4.9 & $2.8 \pm 0.6$ & 12.8 \\
\hline & S-1 + sorafenib & & $776 \pm 87^{\mathrm{e}}$ & 71.7 & 6.0 & $1.1 \pm 0.4 \mathrm{NS}$ & 4.8 \\
\hline \multirow[t]{4}{*}{ NCI-H460 } & Control & - & $2937 \pm 709$ & - & 0.0 & $2.6 \pm 1.3$ & 10.0 \\
\hline & S-1 (8.3) & days $1-14$ & $2206 \pm 279$ & 24.9 & 1.5 & $1.3 \pm 1.8$ & 4.9 \\
\hline & Sorafenib (15) & days $1-14$ & $1327 \pm 173$ & 54.8 & 3.4 & $-0.1 \pm 0.7$ & -0.4 \\
\hline & S-1 + sorafenib & & $1036 \pm 183^{e}$ & 64.7 & 5.4 & $-1.1 \pm 1.2 \mathrm{NS}$ & -4.2 \\
\hline
\end{tabular}

${ }^{\mathrm{a}}$ Tumor volume on day 15 ; ${ }^{\mathrm{b}}$ tumor growth inhibition ratio on day $15 ;{ }^{\mathrm{c}} \mathrm{GDP}$ is the difference in time taken for the RTV to reach 5.0 between the treated and the control groups; ${ }^{\mathrm{d}}$ relative body weight change between days 0 and 15 ; ${ }^{\mathrm{o}}$ overall maximal $\mathrm{P}<0.01$ by closed testing procedure using the Aspin-Welch t-test; NS, overall maximal P $>0.05$ by closed testing procedure using the Aspin-Welch t-test; GDP, growth delay period; RTV, relative tumor volume; $\mathrm{S}-1$, tegafur-gimeracil-oteracil.
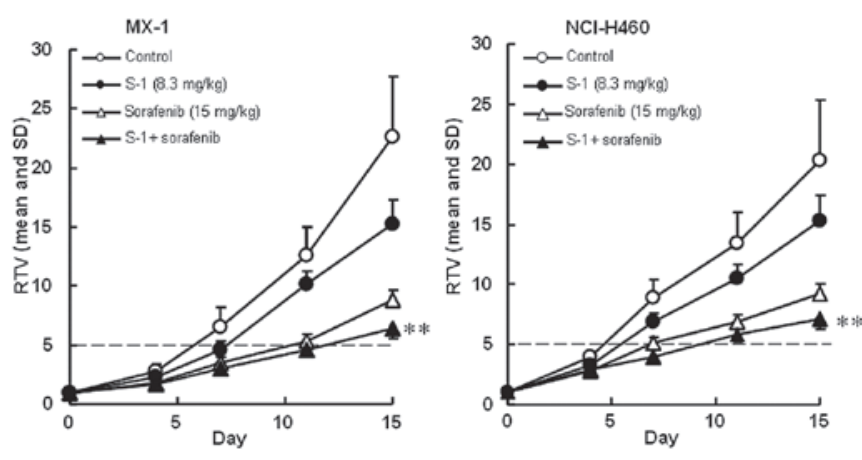

Figure 2. Tumor volume changes in (A) human breast cancer MX-1 cell line and (B) NSCLC NCI-H460 cell line, in vivo. Mice were treated with the vehicle or S-1 at $8.3 \mathrm{mg} / \mathrm{kg}$. Sorafenib at $15 \mathrm{mg} / \mathrm{kg}$ was administered orally once daily on days 1-14, alone or in combination with S-1. The values indicate the means $\pm \mathrm{SD}$ of the RTV $(\mathrm{n}=8){ }^{* *}$ Overall maximal $\mathrm{P}<0.01$ according to a closed testing procedure using the Aspin-Welch t-test. NSCLC, non-small cell lung cancer; RTV, relative tumor volume. S-1, tegafur-gimeracil-oteracil.
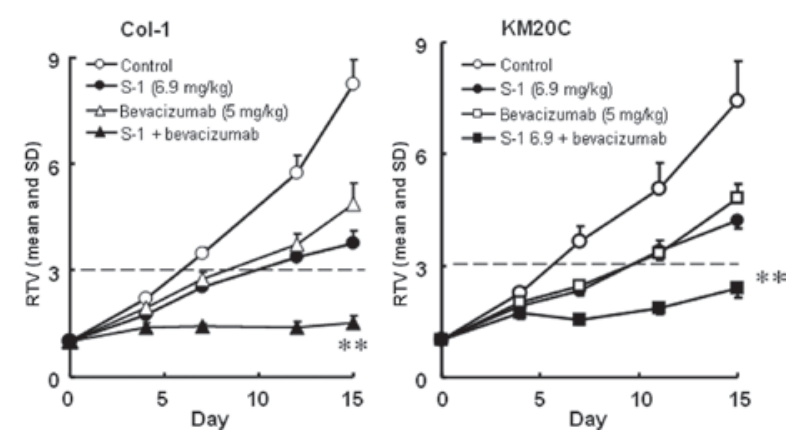

Figure 4. Tumor volume changes in human colorectal cancer, (A) Col-1 and (B) KM20C cell lines, in vivo. Mice were treated with the vehicle (O) or S-1 at $6.9 \mathrm{mg} / \mathrm{kg}$ once daily on days $1-14$ orally. Bevacizumab at $5 \mathrm{mg} / \mathrm{kg}$ was administered intraperitoneally on days $1,4,8$ and 11 , alone or with S- 1 . The tumor volume was measured twice a week. The values indicate the means \pm SD of the RTV $(\mathrm{n}=7) .{ }^{* *}$ Overall maximal $\mathrm{P}<0.01$ according to a closed testing procedure using the Aspin-Welch t-test. RTV, relative tumor volume. S-1, tegafur-gimeracil-oteracil.

The RTV changes of MX-1 and NCI-H460 cancer cell lines treated with sunitinib are shown in Fig. 3. The RTV of the combination group on day 15 was significantly lower than that of either monotherapy group for the MX-1 and NCI-H460 cancer cell lines $(\mathrm{P}<0.01)$. As the GDP values for the combined therapy (5.4 and 3.0 days for the MX-1 and NCI-H460 cancer cell lines, respectively) were almost equivalent to the expected values (4.7 and 3.5 days, respectively), the combination of S-1 with sunitinib was regarded as being not competitive (Table III). As the BWC was not $<-20 \%$ in any group and no significant difference was observed between the combination therapy and either of the monotherapy groups, these combinations appeared to be tolerable. and (B) NSCLC NCI-H460 cell line, in vivo. Mice were treated with the vehicle or S-1 at $8.3 \mathrm{mg} / \mathrm{kg}$. Sunitinib at $20 \mathrm{mg} / \mathrm{kg}$ was administered orally once daily on days $1-14$, alone or in combination with $\mathrm{S}-1$. The values indicate the means \pm SD of the RTV $(n=8)$. ${ }^{* *}$ Overall maximal $\mathrm{P}<0.01$ according to a closed testing procedure using the Aspin-Welch t-test. NSCLC, non-small cell lung cancer; RTV, relative tumor volume. S-1, tegafur-gimeracil-oteracil.
Increased antitumor activity of $S-1$ in combination with targeted antibodies in vivo. The antitumor activities of S-1 and targeted antibodies (cetuximab and bevacizumab) against 
Table III. Antitumor activity and body weight changes in mice implanted with tumors from human breast cancer MX-1 cells or human non-small cell lung cancer NCI-H460 cells, following treatment with S-1 and the multi-kinase inhibitor, sunitinib.

\begin{tabular}{|c|c|c|c|c|c|c|c|}
\hline \multirow{2}{*}{ Tumor } & \multirow[b]{2}{*}{$\begin{array}{c}\text { Drug } \\
(\mathrm{mg} / \mathrm{kg})\end{array}$} & \multirow{2}{*}{ Treatment } & \multirow{2}{*}{$\begin{array}{c}\text { Tumor volume } \\
\left(\mathrm{mm}^{3}, \text { mean } \pm \mathrm{SD}\right)\end{array}$} & \multirow{2}{*}{$\begin{array}{l}\mathrm{TGI}^{\mathrm{b}} \\
(\%)\end{array}$} & \multirow{2}{*}{$\begin{array}{l}\mathrm{GDP}^{\mathrm{c}} \\
\text { (days) }\end{array}$} & \multicolumn{2}{|c|}{ Body weight change $^{\mathrm{d}}$} \\
\hline & & & & & & $(\mathrm{g}$, mean $\pm \mathrm{SD})$ & $(\%)$ \\
\hline \multirow[t]{4}{*}{ MX-1 } & Control & - & $2747 \pm 497$ & - & 0.0 & $4.2 \pm 0.9$ & 19.0 \\
\hline & S-1 (8.3) & days $1-14$ & $1832 \pm 112$ & 33.3 & 1.6 & $3.7 \pm 0.6$ & 16.7 \\
\hline & Sunitinib (20) & days $1-14$ & $1231 \pm 222$ & 55.2 & 3.1 & $3.4 \pm 1.1$ & 15.2 \\
\hline & S-1 + sunitinib & & $811 \pm 148^{\mathrm{e}}$ & 70.5 & 5.4 & $2.4 \pm 1.0 \mathrm{NS}$ & 10.4 \\
\hline \multirow[t]{4}{*}{ NCI-H460 } & Control & - & $2937 \pm 709$ & - & 0.0 & $2.6 \pm 1.3$ & 10.0 \\
\hline & S-1 (8.3) & days $1-14$ & $2206 \pm 279$ & 24.9 & 1.5 & $1.3 \pm 1.8$ & 4.9 \\
\hline & Sunitinib (20) & days $1-14$ & $1826 \pm 232$ & 37.9 & 2.0 & $2.5 \pm 1.0$ & 9.9 \\
\hline & S-1 + sunitinib & & $1282 \pm 120^{\mathrm{e}}$ & 56.4 & 3.0 & $1.5 \pm 0.7 \mathrm{NS}$ & 5.8 \\
\hline
\end{tabular}

${ }^{\mathrm{a}}$ Tumor volume on day 15 ; ${ }^{\mathrm{b}}$ tumor growth inhibition ratio on day $15 ;{ }^{\mathrm{c}} \mathrm{GDP}$ is the difference in time taken for the RTV to reach 5.0 between the treated and the control groups; ${ }^{\mathrm{d}}$ relative body weight change between days 0 and day 15 ; ${ }^{\circ}$ overall maximal $\mathrm{P}<0.01$ by closed testing procedure using the Aspin-Welch t-test; NS, overall maximal P>0 .05 by closed testing procedure using the Aspin-Welch t-test; GDP, growth delay period; RTV, relative tumor growth; S-1, tegafur-gimeracil-oteracil.
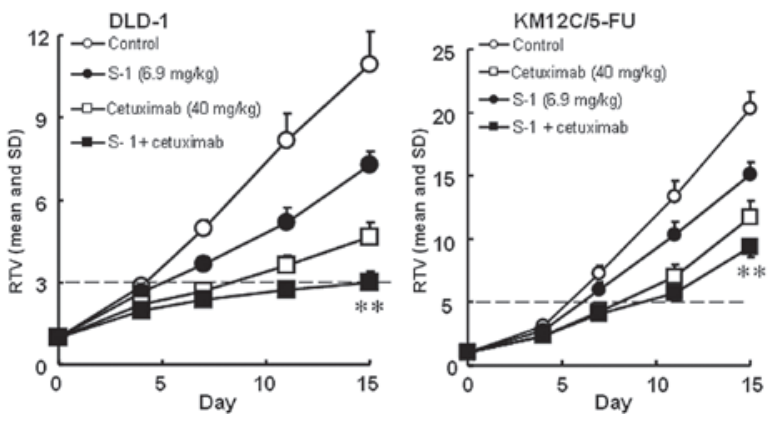

Figure 5. Tumor volume changes in human colorectal cancer, (A) DLD-1, and (B) KM12C/5-FU cell lines, in vivo. Mice were treated with the vehicle or $\mathrm{S}-1$ at $6.9 \mathrm{mg} / \mathrm{kg}$ once daily on days $1-14$ orally. Cetuximab $(40 \mathrm{mg} / \mathrm{kg})$ was intraperitoneally administered on days $1,4,8$ and 11 alone or with S-1. The tumor volume was measured twice a week. The values indicate the means \pm SD of the RTV $(\mathrm{n}=7)$. ${ }^{* *}$ Overall maximal $\mathrm{P}<0.01$ according to a closed testing procedure using the Aspin-Welch t-test. RTV, relative tumor volume. S-1, tegafur-gimeracil-oteracil.

human colorectal cancers were evaluated. The RTV changes of the Col-1, KM20C, DLD-1 and KM12C/5-FU cancer cell lines are shown in Figs. 4 and 5. The tumor volume on day 15, the GDP value (observed or expected) and the BWC between days 0 and 15 are listed in Tables IV and V.

Using a closed testing procedure and the Aspin-Welch t-test, the RTV of the combination groups on day 15 was significantly lower $(\mathrm{P}<0.01)$ than that of either monotherapy group for the 4 examined colorectal cancer cell lines, including the KM12C/5-FU cancer cell lines. Furthermore, the GDP value was increased in the combination groups compared with the monotherapy groups and the observed GDP values for the Col-1 and DLD-1 cancer cell lines were almost twice those expected. As the BWC was not $<-20 \%$ in any of the groups, these combinations appeared to be feasible.

Gene expression levels of DPD. The gene expression level of DPD was measured in 5 xenografts (Table VI). Although the
DPD expression level relative to that of ACTB ranged from 0.031 to 78.3 for the 5 examined xenografts, the antitumor activity of S-1 was potentiated in all the examined cancer cell lines.

\section{Discussion}

We examined combination therapies of S-1 with a number of targeted agents in vivo. The antitumor effect of S-1 was significantly potentiated when used in combination with the examined tyrosine kinase inhibitors (erlotinib, sorafenib and sunitinib) and antibodies (bevacizumab and cetuximab). During these experiments, neither toxic mortality nor a BWC $<-20 \%$ was observed; therefore, these combinations are thought to be feasible.

The cytotoxic activity of 5-FU is mainly dependent on the inhibition of TS, which is the rate-limiting enzyme of deoxythymidine monophosphate synthesis (26). The antitumor effects of 5-FU derivatives are inversely correlated with the activity of TS (27) and resistance against 5-FU is reportedly overcome by the inhibition of TS (28). Tanizaki et al reported that when used in combination with a targeted agent (lapatinib) or antibody (trastuzumab), the antitumor activity of S-1 was potentiated against HER2-overexpressing human gastric tumor cell lines (NCI-N87 and 4-1ST) due to the downregulation of TS via a reduction in E2F1 (17). The agents, erlotinib, sorafenib, sunitinib and cetuximab, have been reported to reduce the level of TS expression (29-33), possibly via the same mechanism, the decrease in TS expression could be the mechanism responsible for the potentiation of the antitumor effect of S-1.

The expression of DPD is inversely correlated with the antitumor activity of 5-FU, but in the present study, the antitumor activity of S-1 was potentiated for all the tumors examined, irrespective of DPD expression. In contrast to other fluoropyrimidines, the antitumor activity of S-1 was not associated with tumoral DPD activity in 30 xenografts (6 gastric, 
Table IV. Antitumor activity and body weight changes in mice implanted with human colorectal cancer tumors from the cell lines, Col-1 or KM20C, following treatment with S-1 and the targeted antibody, bevacizumab.

\begin{tabular}{|c|c|c|c|c|c|c|c|}
\hline \multirow{2}{*}{ Tumor } & \multirow{2}{*}{$\begin{array}{c}\text { Drug } \\
(\mathrm{mg} / \mathrm{kg})\end{array}$} & \multirow{2}{*}{ Treatment } & \multirow{2}{*}{$\begin{array}{c}\text { Tumor volume } \\
\left(\mathrm{mm}^{3}, \text { mean } \pm \mathrm{SD}\right)\end{array}$} & \multirow{2}{*}{$\begin{array}{l}\mathrm{TGI}^{\mathrm{b}} \\
(\%)\end{array}$} & \multirow{2}{*}{$\begin{array}{l}\mathrm{GDP}^{\mathrm{c}} \\
\text { (days) }\end{array}$} & \multicolumn{2}{|c|}{ Body weight change $^{d}$} \\
\hline & & & & & & $(\mathrm{g}$, mean $\pm \mathrm{SD})$ & $(\%)$ \\
\hline \multirow[t]{4}{*}{ Col-1 } & Control & - & $924 \pm 80$ & - & 0.0 & $-1.7 \pm 1.5$ & -7.0 \\
\hline & S-1 (6.9) & days $1-14$ & $423 \pm 43$ & 54.2 & 4.1 & $-2.8 \pm 1.3$ & -11.0 \\
\hline & Bevacizumab (5) & days $1,4,8,11$ & $546 \pm 82$ & 40.9 & 2.6 & $-2.8 \pm 0.8$ & -11.4 \\
\hline & S-1 + bevacizumab & & $172 \pm 21^{\mathrm{e}}$ & 81.3 & $>9.1$ & $-3.0 \pm 1.5 \mathrm{NS}$ & -12.3 \\
\hline \multirow[t]{4}{*}{ KM20C } & Control & - & $1464 \pm 221$ & - & 0.0 & $0.4 \pm 1.2$ & 1.6 \\
\hline & S-1 (6.9) & days $1-14$ & $826 \pm 58$ & 43.6 & 3.9 & $-1.7 \pm 2.3$ & -6.5 \\
\hline & Bevacizumab (5) & days $1,4,8,11$ & $943 \pm 96$ & 35.6 & 3.1 & $0.5 \pm 1.1$ & 2.1 \\
\hline & $\mathrm{S}-1+$ bevacizumab & & $470 \pm 32^{\mathrm{e}}$ & 67.9 & $>9.5$ & $-0.1 \pm 0.7 \mathrm{NS}$ & -0.5 \\
\hline
\end{tabular}

${ }^{a}$ Tumor volume on day 15 ; ${ }^{b}$ tumor growth inhibition ratio on day 15 ; ${ }^{\mathrm{c}} \mathrm{GDP}$ is the difference in time taken for the RTV to reach 3.0 between the treated and the control groups; ${ }^{\mathrm{d}}$ relative body weight change between days 0 and 15 ; ${ }^{\mathrm{e}}$ overall maximal $\mathrm{P}<0.05$ by closed testing procedure using the Aspin-Welch t-test; NS, overall maximal P>0.05 by closed testing procedure using the Aspin-Welch t-test; GDP, growth delay period; RTV, relative tumor volume; $\mathrm{S}-1$, tegafur-gimeracil-oteracil.

Table V. Antitumor activity and body weight changes in mice implanted with human colorectal cancer tumors from the cell lines, DLD-1 and 5-FU-resistant KM12C/5-FU, following treatment with S-1 and the targeted antibody, cetuximab.

\begin{tabular}{|c|c|c|c|c|c|c|c|}
\hline \multirow{2}{*}{ Tumor } & \multirow{2}{*}{$\begin{array}{c}\text { Drug } \\
(\mathrm{mg} / \mathrm{kg})\end{array}$} & \multirow{2}{*}{ Treatment } & \multirow{2}{*}{$\begin{array}{c}\text { Tumor volume } \\
\left(\mathrm{mm}^{3}, \text { mean } \pm \mathrm{SD}\right)\end{array}$} & \multirow{2}{*}{$\begin{array}{l}\mathrm{TGI}^{\mathrm{b}} \\
(\%)\end{array}$} & \multirow{2}{*}{$\begin{array}{l}\mathrm{GDP}^{\mathrm{c}} \\
\text { (days) }\end{array}$} & \multicolumn{2}{|c|}{ Body weight change $^{\mathrm{d}}$} \\
\hline & & & & & & $(\mathrm{g}$, mean $\pm \mathrm{SD})$ & $(\%)$ \\
\hline \multirow[t]{4}{*}{ DLD-1 } & Control & - & $1252 \pm 108$ & - & 0.0 & $-1.9 \pm 1.9$ & -8.0 \\
\hline & S-1 (6.9) & days $1-14$ & $826 \pm 33$ & 34.1 & 1.3 & $-2.0 \pm 1.1$ & -8.8 \\
\hline & Cetuximab (40) & days $1,4,8,11$ & $533 \pm 71$ & 57.4 & 4.4 & $2.2 \pm 1.0$ & 9.6 \\
\hline & $\mathrm{S}-1+$ cetuximab & & $344 \pm 66^{\mathrm{e}}$ & 72.7 & 11.0 & $1.4 \pm 1.2 \mathrm{NS}$ & 6.5 \\
\hline \multirow[t]{4}{*}{ KM12C/5-FU } & Control & - & $2276 \pm 243$ & - & 0.0 & $-1.1 \pm 0.5$ & -4.6 \\
\hline & S-1 (6.9) & days $1-14$ & $1680 \pm 53$ & 26.2 & 1.5 & $-1.8 \pm 1.3$ & -7.1 \\
\hline & Cetuximab (40) & days $1,4,8,11$ & $1310 \pm 165$ & 42.5 & 2.3 & $-1.8 \pm 1.4$ & -3.7 \\
\hline & S-1 + cetuximab & & $1036 \pm 94^{e}$ & 54.5 & 2.4 & $-1.6 \pm 1.1 \mathrm{NS}$ & -8.0 \\
\hline
\end{tabular}

Table VI. DPD mRNA expression levels normalized by $\beta$-actin.

Cell line DPD mRNA expression

\begin{tabular}{lc}
\hline Lu-99 & 78.3 \\
MX-1 & 0.41 \\
Col-1 & 0.031 \\
KM20C & 11.1 \\
KM12C/5-FU & 0.54
\end{tabular}

DPD mRNA expression levels relative to $\beta$-actin $\left(x 10^{4}\right)$. DPD, dihydropyrimidine dehydrogenase.
6 colorectal, 6 breast, 7 lung and 5 pancreatic tumors), unlike the antitumor activity of capecitabine (34). In a large-scale population analysis using 12,783 solid tumors, the DPD protein expression level was shown to be high in NSCLC or pancreatic cancer (35), similar to the results of the present study. From this viewpoint, S-1 combination therapy might be active against tumors with high levels of DPD expression, unlike therapy with other fluoropyrimidines.

Furthermore, the antitumor activity of bevacizumab depends on the inhibition of angiogenesis via the vascular endothelial growth factor (VEGF). In node-positive colon cancer, the reduction of VEGF and the $\mathrm{S}$-phase status reportedly suppress recurrence (36). Unlike other fluoropyrimidines, metabolites 
of tegafur ( $\gamma$-hydroxybutyric and $\gamma$-butyrolactone) reportedly inhibit cancer-induced angiogenesis via a VEGF-related pathway (37); thus, the combination of S-1 with bevacizumab might be promising for other fluoropyrimidines that do not contain tegafur.

In conclusion, we have shown that the combination of S-1 with targeted agents (tyrosine kinase inhibitors or targeted antibodies) is feasible and exerts a potentiated antitumor effect as a result of TS inhibition. These preclinical studies suggest the utility of further clinical trials of S-1-based combination therapy with targeted agents.

\section{References}

1. Popov I, Milicević M and Radosević-Jelić LJ: The addition of bevacizumab to fluoropyrimidine, irinotecan and oxaliplatin-based therapy improves survival for patients with metastatic colorectal cancer (CRC): combined analysis of efficacy. Acta Chir Iugosl 55: $11-16,2008$.

2. Meyerhardt JA, Stuart K, Fuchs CS, Zhu AX, Earle CC, Bhargava P, Blaszkowsky L, Enzinger P, Mayer RJ, Battu S, et al: Phase II study of FOLFOX, bevacizumab and erlotinib as first-line therapy for patients with metastatic colorectal cancer. Ann Oncol 18: 1185-1189, 2007.

3. Boccia RV, Cosgriff TM, Headley DL, Badarinath S and Dakhil SR: A phase II trial of FOLFOX6 and cetuximab in the first-line treatment of patients with metastatic colorectal cancer. Clin Colorectal Cancer 9: 102-107, 2010.

4. Townsley CA, Major P, Siu LL, Dancey J, Chen E, Pond GR, Nicklee T, Ho J, Hedley D, Tsao M, et al: Phase II study of erlotinib (OSI-774) in patients with metastatic colorectal cancer. Br J Cancer 94: 1136-43, 2006.

5. Dal Lago L, D'Hondt V and Awada A: Selected combination therapy with sorafenib: a review of clinical data and perspectives in advanced solid tumors. Oncologist 13: 845-858, 2008.

6. Shirasaka T, Nakano K, Takechi T, Satake H, Uchida J, Fujioka A, Saito H, Okabe H, Oyama K, Takeda S, et al: Antitumor activity of $1 \mathrm{M}$ tegafur-0.4 M 5-chloro-2,4-dihydroxypyridine-1 M potassium oxonate (S-1) against human colon carcinoma orthotopically implanted into nude rats. Cancer Res 56: 2602-2606, 1996.

7. Fukushima M, Satake H, Uchida J, Shimamoto Y, Kato T, Takechi T, Okabe H, Fujioka A, Nakano K, Ohshimo H, et al: Preclinical antitumor efficacy of S-1: A new oral formulation of 5-fluorouracil on human tumor xenografts. Int J Oncol 13 : 693-698, 1998.

8. Sakata Y, Ohtsu A, Horikoshi N, Sugimachi K, Mitachi Y and Taguchi T: Late phase II study of novel oral fluoropyrimidine anticancer drug S-1 (1 M tegafur-0.4 M gimestat-1 M otastat potassium) in advanced gastric cancer patients. Eur J Cancer 34 $1715-1720,1998$

9. Ohtsu A, Baba H, Sakata Y, Mitachi Y, Horikoshi N, Sugimachi K and Taguchi T: Phase II study of S-1, a novel oral fluoropyrimidine derivative, in patients with metastatic colorectal carcinoma. $\mathrm{Br} \mathrm{J}$ Cancer 83: 141-145, 2000

10. Saeki T, Takashima S, Sano M, Horikoshi N, Miura S, Shimizu S, Morimoto K, Kimura M, Aoyama H, Ota J, et al: A phase II study of S-1 in patients with metastatic breast cancer - a Japanese trial by the S-1 Cooperative Study Group, Breast Cancer Working Group. Breast Cancer 11: 194-202, 2002.

11. Muro K, Boku N, Shimada Y, Tsuji A, Sameshima S, Baba H, Satoh T, Denda T, Ina K, Nishina T, et al: Irinotecan plus S-1 (IRIS) versus fluorouracil and folinic acid plus irinotecan (FOLFIRI) as second-line chemotherapy for metastatic colorectal cancer: a randomised phase $2 / 3$ non-inferiority study (FIRIS study). Lancet Oncol 11: 853-860, 2010.

12. Nakashima K, Hironaka S, Boku N, Onozawa Y, Fukutomi A, Yamazaki K, Yasui H, Taku K, Kojima T and Machida N: Irinotecan plus cisplatin therapy and S-1 plus cisplatin therapy for advanced or recurrent gastric cancer in a single institution. Jpn J Clin Oncol 38: 810-815, 2008

13. Koizumi W, Tanabe S, Saigenji K, Ohtsu A, Boku N, Nagashima F, Shirao K, Matsumura Y and Gotoh M: Phase I/II study of S-1 combined with cisplatin in patients with advanced gastric cancer. Br J Cancer 89: 2207-2212, 2003.
14. Narahara H, Fujitani K, Takiuchi H, Sugimoto N, Inoue K, Uedo N, Tsukuma H, Tsujinaka T, Furukawa $\mathrm{H}$ and Taguchi T: Phase II study of a combination of S-1 and paclitaxel in patients with unresectable or metastatic gastric cancer. Oncology 74: 37-41, 2008.

15. Ishigami H, Kitayama J, Kaisaki S, Hidemura A, Kato M, Otani K, Kamei T, Soma D, Miyato H, Yamashita H and Nagawa H: Phase II study of weekly intravenous and intraperitoneal paclitaxel combined with S-1 for advanced gastric cancer with peritoneal metastasis. Ann Oncol 21: 67-70, 2010.

16. Okabe T, Okamoto I, Tsukioka S, Uchida J, Hatashita E, Yamada Y, Yoshida T, Nishio K, Fukuoka M, Jänne PA and Nakagawa K: Addition of S-1 to the epidermal growth factor receptor inhibitor gefitinib overcomes gefitinib resistance in non-small cell lung cancer cell lines with MET amplification. Clin Cancer Res 15: 907-913, 2009.

17. Tanizaki J, Okamoto I, Takezawa K, Tsukioka S, Uchida J, Kiniwa M, Fukuoka M and Nakagawa K: Synergistic antitumor effect of S-1 and HER2-targeting agents in gastric cancer with HER2 amplification. Mol Cancer Ther 9: 1198-1207, 2010.

18. Fukushima M, Fujioka A, Uchida J, Nakagawa F and Takechi T: Thymidylate synthase (TS) and ribonucleotide reductase (RNR) may be involved in acquired resistance to 5-fluorouracil (5-FU) in human cancer xenografts in vivo. Eur J Cancer 37: 1681-1687, 2001.

19. Ikediobi ON, Davies H, Bignell G, Edkins S, Stevens C, O'Meara S, Santarius T, Avis T, Barthorpe S, Brackenbury L, et al: Mutation analysis of 24 known cancer genes in the NCI- 60 cell line set. Mol Cancer Ther 5: 2606-2612, 2006.

20. Higgins B, Kolinsky K, Smith M, Beck G, Rashed M, Adames V, Linn M, Wheeldon E, Gand L, Birnboeck H and Hoffmann G: Antitumor activity of erlotinib (OSI-774, Tarceva) alone or in combination in human non-small cell lung cancer tumor xenograft models. Anticancer Drugs 15: 503-512, 2004

21. Arao T, Fukumoto H, Takeda M, Tamura T, Saijo N, Nishio K: Small in-frame deletion in the epidermal growth factor receptor as a target for ZD6474. Cancer Res 64: 9101-9104, 2004.

22. Prewett MC, Hooper AT, Bassi R, Ellis LM, Waksal HW and Hicklin DJ: Enhanced antitumor activity of anti-epidermal grow th factor receptor monoclonal antibody IMC-C225 in combination with irinotecan (CPT-11) against human colorectal tumor xenografts. Clin Cancer Res 8: 994-1003, 2002.

23. Fox WD, Higgins B, Maiese KM, Drobnjak M, Cordon-Cardo C, Scher HI and Agus DB: Antibody to vascular endothelial growth factor slows growth of an androgen-independent xenograft model of prostate cancer. Clin Cancer Res 8: 3226-3231, 2002

24. Balin-Gauthier D, Delord JP, Rochaix P, Mallard V, Thomas F, Hennebelle I, Bugat R, Canal P and Allal C: In vivo and in vitro antitumor activity of oxaliplatin in combination with cetuximab in human colorectal tumor cell lines expressing different level of EGFR. Cancer Chemother Pharmacol 7: 709-718, 2006.

25. Bauer P, Röhmel J, Maurer W and Hothorn L: Testing strategies in multi-dose experiments including active control. Stat Med 17: 2133-2146, 1988

26. Malet-Martino M and Martino R: Clinical studies of three oral prodrugs of 5-fluorouracil (capecitabine, UFT, S-1): a review. Oncologist: 288-323, 2002.

27. Peters GJ, van der Wilt CL, van Triest B, Codacci-Pisanelli G, Johnston PG, van Groeningen CJ and Pinedo HM: Thymidylate synthase and drug resistance. Eur J Cancer 31A: 1299-1305, 1995.

28. Kadota K, Huang CL, Liu D, Yokomise H, Haba R and Wada H: Combined therapy with a thymidylate synthase-inhibiting vector and S-1 has effective antitumor activity against 5-FU-resistant tumors. Int J Oncol 38: 355-363, 2011.

29. Skvortsov S, Sarg B, Lindner H, Lukas P, Hilbe W, Zwierzina H and Skvortsova I: Cetuximab inhibits thymidylate synthase in colorectal cells expressing epidermal growth factor receptor. Proteomics Clin Appl 2: 908-914, 2008.

30. Giovannetti E, Lemos C, Tekle C, Smid K, Nannizzi S, Rodriguez JA, Ricciardi S, Danesi R, Giaccone G and Peters GJ: Molecular mechanisms underlying the synergistic interaction of erlotinib, an epidermal growth factor receptor tyrosine kinase inhibitor, with the multitargeted antifolate pemetrexed in non-small-cell lung cancer cells. Mol Pharmacol 73: 1290-1300, 2008.

31. Takeuchi A, Shiota M, Tatsugami K, Yokomizo A, Eto M, Inokuchi J, Kuroiwa K, Kiyoshima K and Naito S: Sorafenib augments cytotoxic effect of S-1 in vitro and in vivo through TS suppression. Cancer Chemother Pharmacol 68: 1557-1564, 2011. 
32. Carloni S, Fabbri F, Brigliadori G, Ulivi P, Silvestrini R, Amadori D and Zoli W: Tyrosine kinase inhibitors gefitinib, lapatinib and sorafenib induce rapid functional alterations in breast cancer cells. Curr Cancer Drug Targets 10: 422-431, 2010.

33. Kobunai T, Watanabe T and Fukusato T: Antitumor activity of $\mathrm{S}-1$ in combination with cetuximab on human gastric cancer cell lines in vivo. Anticancer Res 31: 3691-3696, 2011.

34. Ooyama A, Takechi T, Toda E, Nagase H, Okayama Y, Kitazato K, Sugimoto Y, Oka T and Fukushima M: Gene expression analysis using human cancer xenografts to identify novel predictive marker genes for the efficacy of 5-fluorouracil-based drugs. Cancer Sci 97: 510-522, 2006

35. Fukui Y, Oka T, Nagayama S, Danenberg PV, Danenberg KD and Fukushima M: Thymidylate synthase, dihydropyrimidine dehydrogenase, orotate phosphoribosyltransferase mRNA and protein expression levels in solid tumors in large scale population analysis. Int J Mol Med 22: 709-716, 2008.
36. Tang TC, Man S, Xu P, Francia G, Hashimoto K, Emmenegger U and Kerbel RS: Development of a resistance-like phenotype to sorafenib by human hepatocellular carcinoma cells is reversible and can be delayed by metronomic UFT chemotherapy. Neoplasia 12: 928-940, 2010

37. Basaki Y, Chikahisa L, Aoyagi K, Miyadera K, Yonekura K, Hashimoto A, Okabe S, Wierzba K and Yamada Y: $\gamma$-hydroxybutyric acid and 5-fluorouracil, metabolites of UFT, inhibit the angiogenesis induced by vascular endothelial growth factor. Angiogenesis 4: 163-173, 2001. 